\title{
Effects of a low-energy diet on serum insulin and leptin levels and body fat distribution in obese men
}

\author{
A. Djazayery ${ }^{1}$, M. Maddah ${ }^{2}$ and M. R. Eshraghian ${ }^{1}$ \\ ${ }^{1}$ School of Public Health, Tehran University of Medical Sciences, Tehran, Islamic Republic of Iran and ${ }^{2}$ School of Medicine, \\ Rasht University of Medical Sciences, Rasht, Iran
}

Low-energy diets are popular weight-reducing diets (Volek et al., 2004). Extensive studies have been made on the effectiveness of different low-energy diets in weight reduction (Cornier et al., 2005, Kerksick et al., 2009). Investigations have also been conducted on their metabolic effects (Kerksick et al., 2009, Stiegler and Cunliffe, 2006). However, not all their metabolic effects are known. The objective of the present study was to determine the effect of a $5021 \mathrm{~kJ}$ (1200 kcal) diet on anthropometric variables, body fat distribution and serum insulin and leptin concentrations in obese men.

Initially, 100 obese men (age 25.8 (SD 6.0; range 18-43) years; BMI 30-36 kg/m²) who were matched for general characteristics (socioeconomic status, lifestyle, general food habits) were put on a $5021 \mathrm{~kJ}(1200 \mathrm{kcal})$ diet for $8-16$ weeks. The composition of the diet was such that the percentage contributions of fat, protein and carbohydrate to total energy were 25,15 and 60 respectively. All the subjects lost weight, but only those who maintained the reduced weight $(n 63)$ for at least 4 weeks were included in the study. BMI, waist:hip ratio (WHR) and fasting serum leptin and insulin levels were determined at the beginning and at the end of the period. Daily energy and nutrient intakes of the subjects were calculated from two $3 \mathrm{~d}$ food records during the study.

\begin{tabular}{|c|c|c|c|c|c|c|c|}
\hline \multirow[b]{2}{*}{ Variable } & \multicolumn{2}{|c|}{ Initial } & \multicolumn{2}{|c|}{ Final } & \multicolumn{2}{|c|}{ Change } & \multirow[b]{2}{*}{$P<$} \\
\hline & Mean & SD & Mean & SD & Absolute & $\%$ & \\
\hline BW (kg) & 88.7 & 14.0 & 82.6 & 11.7 & -6.1 & 6.8 & 0.001 \\
\hline BMI & 30.6 & 3.5 & 28.5 & 2.8 & -2.1 & 6.8 & 0.001 \\
\hline WHR & 96.0 & 0.04 & 0.94 & 0.04 & -2.0 & 2 & 0.01 \\
\hline Leptin (ng/l) & 118 & 73 & 76 & 31 & -42 & 35.6 & 0.01 \\
\hline Insulin $(\mu \mathrm{IU} / \mathrm{ml})$ & 18.1 & 12.5 & 12.3 & 7.3 & -5.8 & 32.0 & 0.01 \\
\hline
\end{tabular}

As shown in the Table, the $5021 \mathrm{~kJ}(1200 \mathrm{kcal})$ diet brought about a $6.8 \%$ reduction in both body weight and BMI; the reduction in WHR was only $2 \%$. This finding suggests that the diet affected total fat loss, but not fat distribution. There were associations (Pearson correlation) between energy intake and leptin $(0.23, P<0.05)$, BMI $(0.43, P<0.01)$ and WHR $(0.37, P<0.01)$, and between percentage dietary energy from fat and BMI $(0.31, P<0.01)$ and WHR $(0.29, P<0.01)$. However, when percentage dietary energy from fat was corrected for BMI, the associations disappeared. There were also large reductions in the serum levels of leptin (35.6\%) and insulin $(32.0 \%)$, but the only factor associated with the reduction in leptin level was percentage weight loss $\left(R^{2} 0.46 ; \beta 0.167\right.$ (SE 0.084$)$, $P<0.04)$. There was no association between leptin and insulin before weight loss, while after weight loss there was a significant positive correlation.

Based on these findings, it may be concluded that a low-energy diet can bring about desirable metabolic changes in relation to such hormones as leptin and insulin accompanying weight loss in obese men, with no appreciable change in the body fat distribution.

Cornier MA, Donahoo WT, Pereira R et al. Insulin sensitivity determines the effectiveness of dietary macronutrient composition on weight loss in obese women. Obes Res. 2005 Apr;13(4):703-9.

Kerksick C, Thomas A, Campbell B. et al. Effects of a popular exercise and weight loss program on weight loss, body composition, energy expenditure and health in obese women. Nutr Metab (Lond). 2009 May 14;6:23.

Stiegler P, and Cunliffe A. The role of diet and exercise for the maintenance of fat-free mass and resting metabolic rate during weight loss. Sports Med. 2006;36(3):239-62.

Volek J, Sharman M, Gómez A. et al. Comparison of energy-restricted very low-carbohydrate and low-fat diets on weight loss and body composition in overweight men and women. Nutr Metab (Lond). 2004 Nov 8;1(1):13. 